\title{
Diagnosing ovarian cancer
}

\author{
Melissa Walker MD, Mara Sobel MD \\ Cite as: CMAJ 2018 October 22;190:E1259. doi: 10.1503/cmaj.180499
}

CMAJ Podcasts: author interview at https://soundcloud.com/cmajpodcasts/180499-five

\section{Early-stage ovarian cancer is difficult to diagnose \\ because presenting symptoms are vague and nonspecific}

Women with persistent abdominal or pelvic pain, bloating, early satiety, urinary urgency or frequency, or constitutional symptoms require further investigation. ${ }^{1}$ Annual screening in asymptomatic women with a pelvic examination, serum assay for cancer antigen 125 (CA 125) or transvaginal ultrasonography does not improve rates of early diagnosis of ovarian cancer or reduce mortality. ${ }^{2,3}$

2

Transvaginal ultrasonography is the initial imaging modality for women with symptoms of ovarian cancer Small, asymptomatic simple cysts (less than $3 \mathrm{~cm}$ ) seen on ultrasonography are almost certainly benign and do not require gynecologic consultation. ${ }^{4}$ Concerning ultrasonography features are outlined in Box 1.

\section{3}

\section{Serum tumour markers can be helpful when a complex ovarian cyst is identified}

Cancer antigen 125 is elevated (greater than $35 \mathrm{U} / \mathrm{mL}$ ) in most epithelial ovarian cancers and testing should be ordered in all women with concerning findings on ultrasonography. In women who are premenopausal, CA 125 level may be mildly elevated in benign conditions (e.g., endometriosis or fibroids), and this is accounted for in the risk of malignancy index II (RMI II) scoring system (Box 1). In women who are less than 40 years of age, testing for levels of lactate dehydrogenase, $\alpha$-fetoprotein and $\beta$-human chorionic gonadotropin should also be ordered to identify nonepithelial ovarian cancers that are more common in younger women. ${ }^{6}$

\section{4}

The RMI II can be used in primary care to identify women requiring urgent assessment

Risk of malignancy index II incorporates menopausal score (M), ultrasonography score (U) and CA 125 value (Box 1). A score of 200 or more indicates a substantial risk of epithelial ovarian cancer and warrants direct referral to gynecologic oncology.

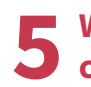

Women with a strong family history of breast, ovarian or colon cancer should be referred to a genetic counsellor A discussion of screening for hereditary syndromes associated with an increased risk of epithelial ovarian cancer is warranted. Compared with the baseline rate of $1.4 \%$ in Canadian women, the average lifetime risk of developing ovarian cancer is $45 \%$ for women with BRCA1 mutations, $12 \%$ for BRCA2 mutations ${ }^{7}$ and up to $24 \%$ for Lynch syndrome. ${ }^{8}$

\begin{tabular}{|c|c|}
\hline Category & Score \\
\hline \multirow[t]{2}{*}{ Menopausal score } & $M=1$ for premenopausal \\
\hline & $M=4$ for postmenopausal \\
\hline \multirow[t]{8}{*}{ Ultrasonography score } & One point each for: \\
\hline & - Multilocular cyst \\
\hline & - Presence of solid components \\
\hline & - Evidence of intraabdominal metastases \\
\hline & - Presence of ascites \\
\hline & - Bilaterality of lesions \\
\hline & $\mathrm{U}=1$ for none or one ultrasonography features \\
\hline & $\mathrm{U}=4$ for two or more ultrasonography features \\
\hline CA 125 & Level in serum $(\mathrm{U} / \mathrm{mL})$ \\
\hline \multicolumn{2}{|c|}{$\begin{array}{l}\text { Note: } \mathrm{CA}=\text { cancer antigen, } \mathrm{RMI}=\text { risk of malignancy index. Adapted from Journal of } \\
\text { Obstetrics and Gynaecology Canada, Vol. } 40 \text {, Tien Le and Christopher Giede, No. } \\
\text { 230-Initial evaluation and referral guidelines for management of pelvic/ovarian cysts, } \\
\text { e223-29, 2018, with permission from Elsevier. } \\
\text { 'RMI II score }=\mathrm{M} \times \mathrm{U} \times \mathrm{CA} 125 \text {. A score of } 200 \text { or more warrants direct referral to } \\
\text { gynecologic oncology. }\end{array}$} \\
\hline
\end{tabular}

\section{References}

1. Goff BA, Mandel LS, Melancon CH, et al. Frequency of symptoms of ovarian cancer in women presenting to primary care clinics. JAMA 2004;291:2705-12.

2. Buys SS, Partridge E, Black A, et al.; PLCO Project Team. Effect of screening on ovarian cancer mortality: the Prostate, Lung, Colorectal and Ovarian (PLCO) Cancer Screening Randomized Controlled Trial. JAMA 2011;305:2295-303.

3. Jacobs IJ, Menon U, Ryan A, et al. Ovarian cancer screening and mortality in the UK Collaborative Trial of Ovarian Cancer Screening (UKCTOCS): a randomised controlled trial. Lancet 2016;387:945-56.

4. Levine D, Brown DL, Andreotti RF, et al. Management of asymptomatic ovarian and other adnexal cysts imaged at US: Society of Radiologists in Ultrasound Consensus Conference Statement. Radiology 2010;256:943-54.

5. Le T, Giede C. No. 230-initial evaluation and referral guidelines for management of pelvic/ovarian masses. J Obstet Gynaecol Can 2018;40:e223-9.

6. American College of Obstetricians and Gynecologists' Committee on Practice Bulletins-Gynecology. Practice Bulletin No. 174: Evaluation and management of adnexal masses. Obstet Gynecol 2016;128:e210-26.

7. Kuchenbaecker KB, Hopper JL, Barnes DR, et al. Risks of breast, ovarian, and contralateral breast cancer for BRCA1 and BRCA2 mutation carriers. JAMA 2017;317:2402-16.

8. Bonadona V, Bonaïti B, Olschwang S, et al.; French Cancer Genetics Network. Cancer risks associated with germline mutations in $M L H 1, M S H 2$, and $M S H 6$ genes in Lynch syndrome. JAMA 2011;305:2304-10.

Competing interests: None declared.

This article has been peer reviewed.

Affiliations: Department of Obstetrics and Gynecology (Walker, Sobel), Faculty of Medicine, University of Toronto; Department of Obstetrics and Gynecology (Walker, Sobel), Mount Sinai Hospital, Toronto, Ont.

Correspondence to: Melissa Walker, Melissa.walker@mail.utoronto.ca 